\title{
Self-Healing, High-Permittivity Silicone Dielectric Elastomer
}

\author{
Madsen, Frederikke Bahrt; Yu, Liyun; Skov, Anne Ladegaard
}

Published in:

ACS Macro Letters

Link to article, DOI:

10.1021/acsmacrolett.6b00662

Publication date:

2016

Document Version

Peer reviewed version

Link back to DTU Orbit

Citation (APA):

Madsen, F. B., Yu, L., \& Skov, A. L. (2016). Self-Healing, High-Permittivity Silicone Dielectric Elastomer. ACS Macro Letters, 5, 1196-1200. https://doi.org/10.1021/acsmacrolett.6b00662

\section{General rights}

Copyright and moral rights for the publications made accessible in the public portal are retained by the authors and/or other copyright owners and it is a condition of accessing publications that users recognise and abide by the legal requirements associated with these rights.

- Users may download and print one copy of any publication from the public portal for the purpose of private study or research.

- You may not further distribute the material or use it for any profit-making activity or commercial gain

- You may freely distribute the URL identifying the publication in the public portal

If you believe that this document breaches copyright please contact us providing details, and we will remove access to the work immediately and investigate your claim. 


\title{
Self-healing, high-permittivity silicone dielectric elastomer
}

\author{
Frederikke Bahrt Madsen, Liyun Yu and Anne Ladegaard Skov* \\ Danish Polymer Centre, Department of Chemical and Biochemical Engineering, Technical University of Denmark, \\ DTU, Søltofts Plads, Building 227, 280o Kgs. Lyngby, Denmark
}

\begin{abstract}
Currently used dielectric elastomers do not have the ability to self-heal after detrimental events such as tearing or electrical breakdown, which are critical issues in relation to product reliability and lifetime. In this paper we present a self-healing dielectric elastomer which additionally possesses high dielectric permittivity and consists of an interpenetrating polymer network of silicone elastomer and ionic silicone species which are cross-linked through proton exchange between amines and acids. The ionically cross-linked silicone provides self-healing properties after electrical breakdown or cuts made directly to the material, due to the reassembly of the ionic bonds that are broken during damage. The dielectric elastomers presented in this paper pave the way to increased lifetimes and the ability of dielectric elastomers to survive millions of cycles in high-voltage conditions.
\end{abstract}

Dielectric elastomers have the ability to mimic human muscles, because they possess properties such as large strains, high-energy densities and fast responses and are therefore often referred to as 'artificial muscles'. ${ }^{1-3}$ The most obvious human muscle property that current dielectric elastomers lack is the ability to self-heal, as human muscles are able to perform this feat and regenerate after an injury, before continuing to function throughout our lives. In a dielectric elastomer, that "injury" may be dielectric breakdown, and current elastomer materials are not able to survive this phenomenon, thereby leading to permanent failure of the dielectric elastomer transducer.

Dielectric elastomers consist of a thin elastomer film $(<30 \mu \mathrm{m})$ sandwiched between two very thin, flexible electrodes and forming a stretchable capacitor. When a voltage is applied to the electrodes electrostatic forces are formed that reduce the elastomer in thickness and which in turn expands in area. Movement, i.e. actuation, is thus created by electrical stimulus - much like in a human muscle. In order to actuate currently used materials, however, high driving voltages are needed, often in the order of kilovolts. This leaves the elastomer susceptible to premature electrical breakdown as a result of the local electric field exceeding the dielectric breakdown strength of the elastomer. ${ }^{4}$ The risk of breakdown is furthermore increased if defects or imperfections exist in the elastomer. Moreover, dielectric or viscous losses may lead to breakdown if the heat generated by these losses exceeds heat dissipated into the surrounding area. 5 Elastomers with few imperfections and low losses are therefore in high demand. High-permittivity silicone materials are also required if higher actuation strains at lower voltages are desired. This demand is in stark contrast to the desire for materials with a high tolerance to electrical breakdown, since high-permittivity materials often have higher degrees of imperfection and higher losses. ${ }^{3}$ The solution is the creation of high-permittivity, self-healing elastomer materials for which both lower electrical fields are needed to actuate the dielectric elastomer, and the elastomer is able to self-heal if a breach occurs.

Only a few approaches to self-healing dielectric elastomers have been presented to date, ${ }^{6-8}$ and although multiple approaches to self-healing polymers and elastomers based on for example metal complexes ${ }^{9}$, ionomers ${ }^{10,11}$, hydrogen-bonding ${ }^{12,13}, \pi-\pi$ stacking ${ }^{14}$ and supramolecular assemblies ${ }^{15,16}$ have been developed, there has been no focus on dielectric properties. ${ }^{17}$ Recently, we presented a novel class of interpenetrating silicone and ionic networks exhibiting increased dielectric permittivity. ${ }^{18}$ We have now optimized these networks, using a different silicone cross-linking chemistry based on condensation silicones which are not, unlike platinum-cured silicones, inhibited by ionic network constituents, thus leading to significantly better cured networks. In this paper we demonstrate that the interpenetrating ionic network displays self-healing abilities, and then we move on to explain how it is used to help dielectric elastomers self-heal after a detrimental breakdown event or other type of damage to the elastomer.

Self-healing dielectric elastomers were created from two different networks, namely a silicone and an ionic network, and then combined to create an interpenetrating polymer network (IPN). A number of IPNs were prepared by mixing 

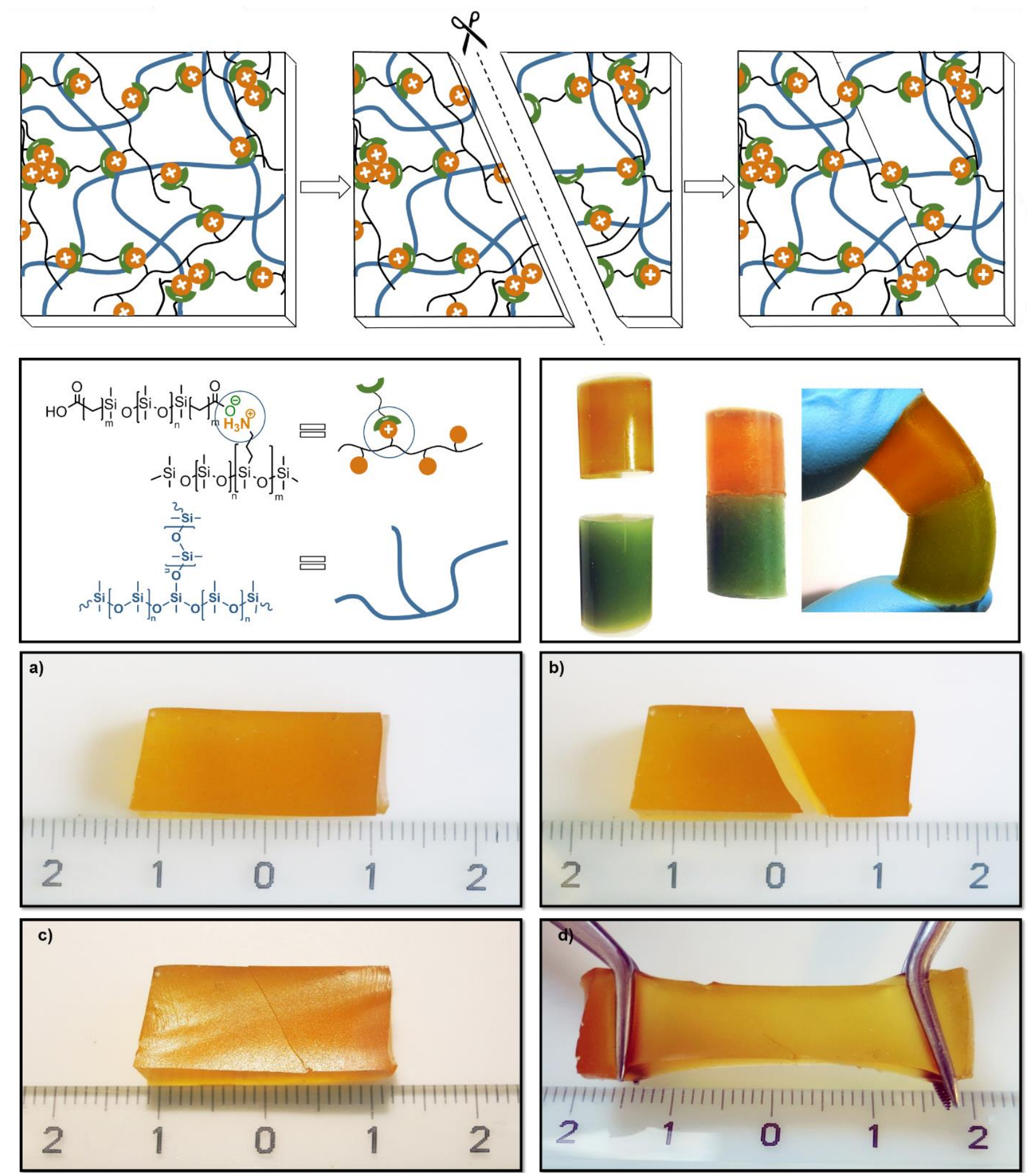

Figure 1. Chemistry of the prepared IPNs and their self-healing abilities. Top and middle left: chemistry of the IPNs, which consist of interpenetrating networks of traditional silicone cured by condensation chemistry and an ionic silicone network cured by the formation of ionic bonds between protonated amines and acids. Middle right: two different sample pieces are also able to self-heal (reassemble), here illustrated by one piece coloured in green which was made using 1 phr green pigment (PGGRNor from Flourochem). The sample is able to withstand bending, straining and compression after self-healing. a) Shows a film after curing and before any inflicted damage. b): A cut is made in the film. c): After thermal treatment the sample is able to self-heal due to the reassembly of the ionic bonds that were broken. Initial adhesion is due to adhesion from the silicone network part whereas the permanent reattachment is due to the reformation of ionic bonds after the thermal treatment. $d$ ): Self-healed samples are still able to attain high strains. 
Table 1. Results of electrical breakdown measurements, determined Weibull parameters as well as $\mathbf{r}^{2}$.

\begin{tabular}{|l|l|l|l|l|l|}
\hline No. & Name & $\begin{array}{l}E_{\mathrm{B}} \\
(\mathrm{V} / \mu \mathrm{m})\end{array}$ & $\beta$ & $\begin{array}{l}\eta \\
(\mathrm{V} / \mu \mathrm{m})\end{array}$ & $\begin{array}{l}\mathrm{r}^{2} \text { of } \\
\text { Weibull fit }\end{array}$ \\
\hline$\# 1$ & Si-A & $53 \pm 2$ & 34.5 & 54.1 & 0.94 \\
\hline$\# 2$ & Si-A_IN10 & $55 \pm 2$ & 27.8 & 55.8 & 0.94 \\
\hline$\# 3$ & Si-A_IN20 & $57 \pm 3$ & 23.4 & 57.8 & 0.94 \\
\hline$\# 4$ & Si-A_IN30 & $56 \pm 5$ & 14.6 & 58.3 & 0.93 \\
\hline$\# 5$ & Si-B & $45 \pm 3$ & 19.8 & 46.1 & 0.96 \\
\hline$\# 6$ & Si-B_IN10 & $53 \pm 4$ & 14.8 & 55.1 & 0.89 \\
\hline$\# 7$ & Si-B_IN20 & $46 \pm 6$ & 11.0 & 48.3 & 0.79 \\
\hline$\# 8$ & Si-B_IN30 & $39 \pm 9$ & 6.6 & 41.3 & 0.72 \\
\hline
\end{tabular}

the silicone elastomer part, which consists of hydroxylterminated polydimethylsiloxane (PDMS) (Si-A: $\bar{M}_{w} \approx$ 31,00o $\mathrm{g} \mathrm{mol}^{-1}$ or Si-B: $\bar{M}_{w} \approx 70$,ooo $\mathrm{g} \mathrm{mol}^{-1}$ ), a methyltrimethoxysilane cross-linker and a dibutyltin-diacetate catalyst, together with the ionic network part, consisting of aminopropyl-functional silicone $\left(\bar{M}_{w} \approx 4500 \mathrm{~g} \mathrm{~mol}^{-1}\right)$, with an average of four amino groups, and telechelic carboxylic acid-functional silicone $\left(\bar{M}_{w} \approx 1000 \mathrm{~g} \mathrm{~mol}^{-1}\right)$. Concentrations of the ionic network (IN) parts of the IPNs varied from 10-30 wt\% (IN1o-IN30) within the silicone matrices (Si-A or $\mathrm{Si}-\mathrm{B})$. The films were coated in thicknesses of $1 \mathrm{~mm}$ and $200 \mu \mathrm{m}$, respectively. The condensation silicone part of the IPN was cured in a high-humidity oven ( $80 \%$ humidity for three days at RT), after which the ionic network part of the interpenetrating network was cured in a normal oven at $120^{\circ} \mathrm{C}$ for three days. This rather slow cure is due to reduced mobility of the ionic components in the crosslinked silicone matrix. The degree of cure and mechanical integrity of the films were confirmed and evaluated by their linear viscoelastic properties, measured using an ARES-G2 rheometer with frequency sweeps from $100 \mathrm{~Hz}$ to o.o1 $\mathrm{Hz}$ at an ambient temperature (details and resulting rheological curves in ESI). Longer curing times did not lead to changes in moduli and the chosen reaction time was thus evaluated to be appropriate. During the second curing step protonation of the amino groups occurred and ionic bonds formed between the amino groups and the acid groups, as shown in Figure 1.

X-ray diffraction measurements (presented in ESI) confirmed that the prepared materials were homogenous and that the ionic species were not present as larger clusters. The ionic species will however be present in the material in a statistical distribution and some segregation of ionic species will occur. This is also illustrated in the top figure of Figure 1. Details of the material preparation are given as ESI. The resulting IPN elastomers as well as the control samples, i.e. pure $\mathrm{Si}-\mathrm{A}$ and $\mathrm{Si}-\mathrm{B}$, are shown in supporting information, in which it is clear that the samples look increasingly orange coloured in line with the increasing concentration of the ionic network. This phenomenon is typically associated with amine oxidation and, under the conditions of the experiment, could not be avoided. However, as seen, they all remain transparent and homogenous. All samples, including a pure ionic network sample, were shown to be hydrophobic by static contact angle measurements and furthermore swelling experiments showed that none of the samples swell in water (data presented as ESI).

The homogeneity of the films was assessed further through electrical breakdown strength measurements performed on an in-house-built device based on international standards. ${ }^{19}$ A step-wise increasing voltage was applied (50$100 \mathrm{~V} / \mathrm{step}$ ) at a rate of 0.5-1.0 step/s. Each sample was subjected to eight electrical breakdown measurements, and an average of the values was indicated as the electrical breakdown strength thereof. Electrical breakdown strength was analysed statistically through a Weibull distribution analysis, from which the probability of breakdown can be determined. The linearized Weibull cumulative distribution function $\left(F\left(E_{\mathrm{B}}\right)\right)$ is given as:

$$
\ln \left[-\ln \left(1-F\left(E_{B}\right)\right)\right]=\beta \cdot \ln \left(E_{B}\right)-\beta \cdot \ln (\eta)
$$

where $E_{\mathrm{B}}$ is the measured electrical breakdown strength, $\eta$ is the scale parameter and $\beta$ is the shape parameter. In a probability plot, the shape parameter, $\beta$, is then equal to the slope of the regressed line. It is desirable to have as large a $\beta$ value as possible, since this means that the breakdown values fall within a narrow range of voltages. A high $\beta$ value can also give an indication about microscale homogeneity, since electrical breakdown strength measurements are very sensitive to local defects and imperfections. ${ }^{20}$ The scale parameter, $\eta$, is determined from the distribution at which $63.2 \%$ of the samples have broken down. The results of the electrical breakdown measurements and the Weibull distribution results with $\beta, \eta$ and a linear regression value $\left(\mathrm{r}^{2}\right)$ are shown in Table 1 , whereas raw data and Weibull plots are given as ESI. For control samples Si$\mathrm{A}$ and $\mathrm{Si}-\mathrm{B}$, electrical breakdown strengths were determined to be $53 \pm 2 \mathrm{~V} / \mu \mathrm{m}$ and $45 \pm 3 \mathrm{~V} / \mu \mathrm{m}$, respectively. The $\mathrm{Si}-\mathrm{B}$ control sample is softer than $\mathrm{Si}$-A due to lower crosslinking density and thus possesses slightly lower electrical breakdown strength. It is well known that the electrical breakdown performance of dielectric elastomers is influenced strongly by material conditions such as the Young's modulus, ${ }^{21}$ applied pre-strain ${ }^{20,22-24}$ and elastomer thickness. ${ }^{22,24}$ Electrical breakdown strength values remain constant within experimental uncertainty, irrespective of the concentration of the added ionic network, the presence of which in the investigated concentrations therefore does not affect the overall breakdown strength of the materials.

The shape parameter $\beta$, however, is seen to be influenced by the concentration of the ionic network, since it decreases in line with increasing concentration. This indicates that there may be some tendencies for microscale phase separation between the silicone network and the ionic network at higher ionic network concentration. The interpenetrating structure of the materials, nevertheless, makes it difficult for the two networks to phase separate completely, due to their interlocked nature and the very low rate of flow which ensures long-term stability. This is true at room temperature, whereas at higher temperature, for example during the self-healing process, the ionic parts are able to 'flow' or 'migrate' and self-heal the material. The lower $\beta$ values obtained for Si-B-containing materials are most likely due to the viscosity of the pre-cured silicone, 

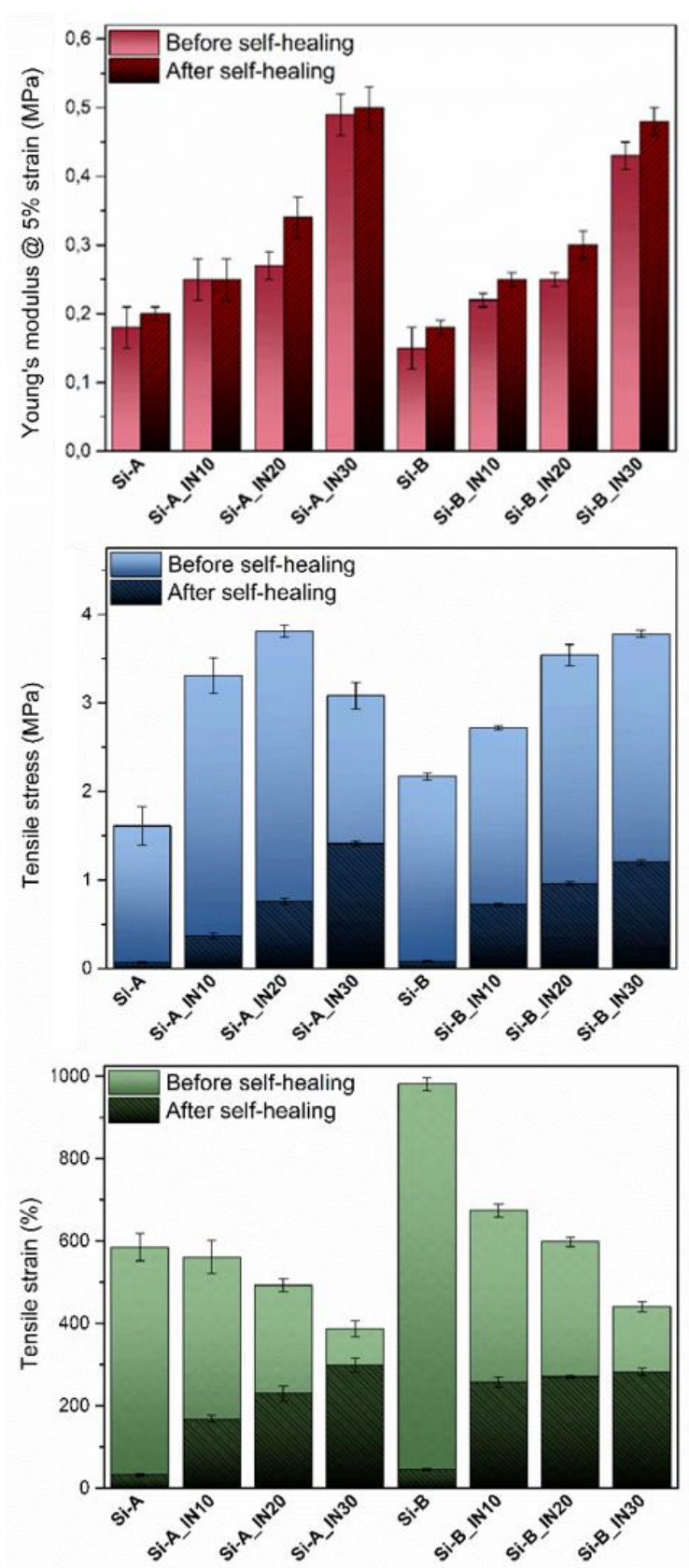

Figure 2. Graphical illustration of mechanical properties before and after self-healing.

which in this case is rather high and thus leads to mixing and ultimately inhomogeneity - issues. All $\beta$ values, however, were high enough to indicate little variance in data and a high degree of confidence and reliability.

The dielectric properties of the films were measured using dielectric relaxation spectroscopy (DRS) on a Novocontrol Alpha-A high-performance frequency analyser in the frequency range $10^{-1}-10^{6} \mathrm{~Hz}$. Resulting dielectric spectra are shown as ESI. The control samples Si-A and Si-B both possess relative dielectric permittivity in the range $\varepsilon^{\prime}=3.1-$ 3.2 and, as expected, dielectric permittivity increases in line with the increasing concentration of the ionic network, reaching $\varepsilon^{\prime}=5.8$ and $\varepsilon^{\prime}=6.3$ at $0.1 \mathrm{~Hz}$ for Si-A_IN30 and SiB_IN30, respectively. In both cases this approximately represents a doubling of dielectric permittivity. The dielectric loss factor, $\tan \delta$, increases in line with increasing ionic network concentration, but it remains lower than 0.15 even at low frequencies $(0.1 \mathrm{~Hz})$; furthermore, the elastomers remain non-conductive. Combined with the dielectric breakdown results, the produced IPNs are consequently ideal candidates for high-permittivity dielectric elastomers. It should be noted that insufficient curing affects the dielectric properties of such condensation cure silicone elastomers, since unreacted polar groups tend to increase both permittivity, losses and conductivity in undesired ways. Proper curing, such as that carried out in these experiments, eliminates this problem (details in ESI).

The self-healing capabilities of the materials were tested after applying cuts to the materials and after electrical breakdown. The tensile properties of the samples before and after self-healing were measured on a series of thin elastomer films (100-200 $\mu \mathrm{m})$ in order to determine Young's moduli and tensile strengths by uniaxial extensional rheology, using an ARESG2 rheometer with an SER2 geometry, as described by Zhang et al. ${ }^{25}$ The test specimen was elongated uniaxially at a steady Hencky strain rate of $0.01\left(\mathrm{~s}^{-1}\right)$ until sample failure in the middle part. Young's moduli were obtained from the tangent of the stress-strain curves at a $5 \%$ strain. After measuring the initial tensile properties, the samples were clipped in the middle, reattached and treated in an oven for 12 hours at $120^{\circ} \mathrm{C}$, although significantly shorter self-healing times are also possible. Four hours, for example, is enough to self-heal a sample where the two sample parts have a large contact area. The samples' stress-strain properties were re-tested thereafter. The results of the tensile tests, with Young's moduli at a $5 \%$ strain, tensile stress and tensile strain before and after self-healing can be found in Figure 2. Stress-strain curves are shown as ESI. Young's moduli increase in line with increasing ionic network concentrations, due to the higher cross-linking density of the rather short-chain ionic network. This ultimately leads to a stiffer material with a higher Young's modulus. All materials are nonetheless soft and very stretchable, irrespective of ionic network concentration, with tensile strains well above $350 \%$ for both $\mathrm{Si}-\mathrm{A}$ and $\mathrm{Si}-\mathrm{B}$. The exceptional extensibility of the samples after self-healing is seen clearly in Figure 1. As highlighted in Figure 2, all samples containing ionic networks have the ability to self-heal after thermal treatment, whereas the control samples have very little ability, with less than $6 \%$ strain and stress recovery. This minimal recovery is simply due to adhesive forces and very small amounts of previously unreacted species and not to actual self-healing of the ionic network. The higher the content of the ionic network, the higher the self-healing abilities. This is especially pronounced for the IPN system with $\mathrm{Si}-\mathrm{A}$, where a $30 \mathrm{wt} \%$ ionic network leads to as much as $77 \%$ strain recovery and close to $300 \%$ obtainable strain, which is significant given the fact that the samples were cut in half and then reassembled. The curing conditions strongly influenced the mechanical properties and self-healing abilities of the samples (more details in ESI). Incomplete curing in the initial curing step for example led to a higher degree of self-healing but this was simply attributed to unreacted species 


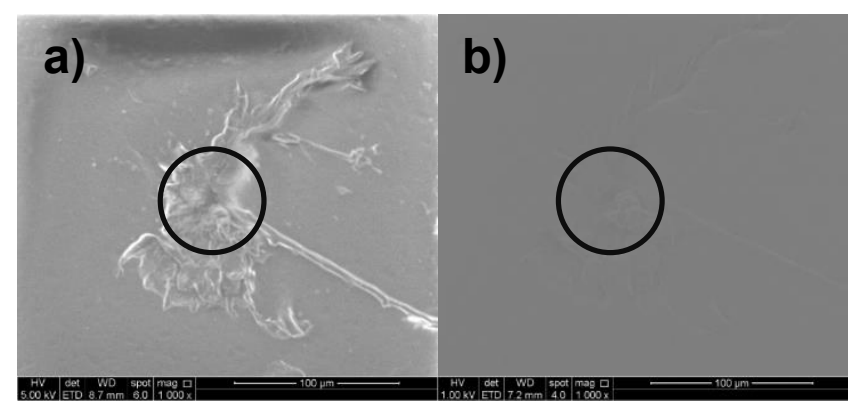

Figure 3. SEM images of a sample (Si-A_IN10) that has been subjected to dielectric breakdown in a) and subsequently selfhealed after a treatment at $120^{\circ} \mathrm{C}$ for 6 hours in b). The surface of the sample has very obviously smoothened out after selfhealing, and the pinhole in the middle of the black circle has closed up.

from the silicone network part of the samples and not actual self-healing from the ionic network part. Not only do the materials possess the ability to self-heal after mechanical damage, but the prepared IPNs are also capable of selfhealing after a detrimental electrical breakdown event. This is clearly illustrated in the SEM images shown in Figure 3 a) where a sample ( $\mathrm{Si}$-A_IN10) was subjected to electrical breakdown. Significant damage and a distinct pinhole in the sample are seen clearly and marked with a black circle. After thermal treatment it can be seen in Figure $3 \mathrm{~b}$ ) that the damage to the sample has flattened out and the pinhole has closed up. For small breakdown pinholes it was observed that heat generated during the use of the dielectric elastomer transducer itself (i.e. due to losses) may be sufficient to self-heal the breakdown and allow for the continued operation of the transducer, i.e. true self-healing ability with no external stimulus required. Several other similar images are shown as ESI.

The road towards the full commercialisation of dielectric elastomers transducers still faces major challenges, particularly in improving the lifetime. This issue is crucial even in the early stages of manufacturing, where the very thin dielectric elastomer films $(<30 \mu \mathrm{m})$ need to survive being released from carrier webs without detrimental tearing. In addition, the tearing of films after electrical breakdown is also a critical problem in relation to product reliability and lifetime. Self-healing abilities therefore play a major role in both the fabrication and the use of thin dielectric elastomer films. Consequently, the materials presented in this paper pave the way towards dielectric elastomers with significantly increased lifetimes and the ability to survive millions of high voltage cycles without compromising other important properties required for actuation performance.

\section{ASSOCIATED CONTENT}

Supporting Information. Experimental details and preparation methods, photos of samples, rheology data, XRD data, electrical breakdown data, dielectric spectroscopy data, tensile test data, contact angle and swelling measurements and photos of self-healing. This material is available free of charge via the Internet at http://pubs.acs.org.

\section{AUTHOR INFORMATION}

Corresponding Author *E-mail: al@kt.dtu.dk.

\section{ACKNOWLEDGMENT}

The authors gratefully acknowledge the financial support of the Danish Council for Independent Research and Innovationsfonden Denmark. Kenny Ståhl, DTU Chemistry, is appreciatively accredited for XRD measurements

\section{REFERENCES}

(1) Pelrine, R.; Kornbluh, R.; Pei, Q.; Joseph, J. Science 2ooo, 287 (5454), 836-839.

(2) Brochu, P.; Pei, Q. Macromol. Rapid Commun. 2010, 31 (1), 10-36.

(3) Madsen, F. B.; Daugaard, A. E.; Hvilsted, S.; Skov, A. L. Macromol. Rapid Commun. 2016, 37 (5), 378-413.

(4) Suo, Z. Acta Mech. Solida Sin. 2010, 23 (6), 549-578.

(5) Zakaria, S.; Morshuis, P. H. F.; Benslimane, M. Y.; Gernaey, K. V.; Skov, A. L. Proc. SPIE 2014, 9056, 90562V.

(6) Dünki, S. J.; Ko, Y. S.; Nüesch, F. A.; Opris, D. M. Adv. Funct. Mater. 2015, 25 (16), 2467-2475.

(7) Hunt, S.; McKay, T. G.; Anderson, I. A. Appl. Phys. Lett. 2014, 104 (11), 113701

(8) Li, C.-H.; Wang, C.; Keplinger, C.; Zuo, J.-L.; Jin, L.; Sun, Y.; Zheng, P.; Cao, Y.; Lissel, F.; Linder, C.; You, X.-Z.; Bao, Z. Nat. Chem. 2016, 8, 618-624.

(9) Bode, S.; Bose, R. K.; Matthes, S.; Ehrhardt, M.; Seifert, A.; Schacher, F. H.; Paulus, R. M.; Stumpf, S.; Sandmann, B.; Vitz, J.; Winter, A.; Hoeppener, S.; Garcia, S. J.; Spange, S.; van der Zwaag, S.; Hager, M. D.; Schubert, U. S. Polym. Chem. 2013, 4 (18), 4966-4973.

(10) Varley, R. J.; van der Zwaag, S. Acta Mater. 2oo8, 56 (19), 5737-5750

(11) Hohlbein, N.; Shaaban, A.; Bras, A. R.; Pyckhout-Hintzen, W.; Schmidt, A. M. Phys. Chem. Chem. Phys. 2015, 17 (32), 21005-21017.

(12) Cordier, P.; Tournilhac, F.; Soulié-Ziakovic, C.; Leibler, L. Nature 2008, 451 (7181), 977-980.

(13) Chen, S.; Mahmood, N.; Beiner, M.; Binder, W. H. Angew. Chemie - Int. Ed. 2015, 54 (35), 10188-10192.

(14) Burattini, S.; Merino, H.; Weng, W.; Rowan, S. J. J. Am. Chem. Soc. 2010, 132 (10), 12051-12058.

(15) Herbst, F.; Seiffert, S.; Binder, W. H. Polym. Chem. 2012, 3 (11), 3084

(16) Yan, T.; Schröter, K.; Herbst, F.; Binder, W. H.; ThurnAlbrecht, T. Sci. Rep. 2016, 6 (September), 32356.

(17) Herbst, F.; Döhler, D.; Michael, P.; Binder, W. H. Macromol. Rapid Commun. 2013, 34 (3), 203-220.

(18) Yu, L.; Madsen, F. B.; Hvilsted, S.; Skov, A. L. RSC Adv. 2015, 5 (61), 49739-49747.

(19) Carpi, F.; Anderson, I.; Bauer, S.; Frediani, G.; Gallone, G.; Gei, M.; Graaf, C.; Jean-Mistral, C.; Kaal, W.; Kofod, G.; Kollosche, M.; Kornbluh, R.; Lassen, B.; Matysek, M.; Michel, S.; Nowak, S.; O’Brien, B.; Pei, Q.; Pelrine, R.; Rechenbach, B.; Rosset, S.; Shea, H. Smart Mater. Struct. 2015, 24 (10), 105025 .

(20) Zakaria, S.; Morshuis, P. H. F.; Benslimane, M. Y.; Yu, L.; Skov, A. L. Smart Mater. Struct. 2015, 24 (5), 55009.

(21) Kollosche, M.; Stoyanov, H.; Ragusch, H.; Risse, S.; Becker, A.; Kofod, G. 1oth IEEE Int. Conf. Solid Dielectr. 2010, 1-4.

(22) Gatti, D.; Haus, H.; Matysek, M.; Frohnapfel, B.; Tropea, C.; Schlaak, H. F. Appl. Phys. Lett. 2014, 104 (5), 052905.

(23) Tröls, A.; Kogler, A.; Baumgartner, R.; Kaltseis, R.; Keplinger, C.; Schwödiauer, R.; Graz, I.; Bauer, S. Smart Mater. Struct. 2013, 22 (10), 104012.

(24) Huang, J.; Shian, S.; Diebold, R. M.; Suo, Z.; Clarke, D. R. Appl. Phys. Lett. 2012, 101 (12), 122905.

(25) Zhang, X.-M.; Li, H.; Chen, W.-X.; Feng, L.-F. Polym. Eng. Sci. 2012, 52 (8), 1740-1748. 


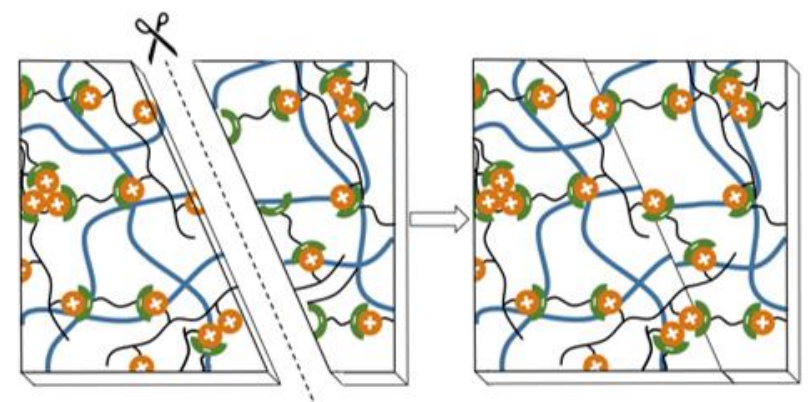

